\title{
Best Practices for Employees' Workplace Health and Safety: Mediating Role of Organizational Culture
}

\author{
Shadrach OMOFOWA ${ }^{1}$, Rita Omon AKHIDUE-OGOGO ${ }^{2}$, Chijioke NWACHUKWU ${ }^{3}$, \\ Trung Minh $\mathrm{LAM}^{4}$ \\ \{ shadrachomofowa@gmail.com¹, ritaomon2002@yahoo.com², cesogwa.nwachukwu@huparis.eu ${ }^{3}$, \\ trung.lm@vlu.edu.vn $\left.{ }^{4}\right\}$ \\ ${ }^{1}$ Global Business School, ${ }^{2}$ University of Benin, Nigeria. ${ }^{3}$ Horizons University Paris and Department \\ of Financial Technologies, South Ural State University Chelyabinsk, Russia. ${ }^{4}$ Corresponding Author. \\ Lecturer, Faculty of Business Administration, Van Lang University, Vietnam
}

\begin{abstract}
To sustain the competitive edge, competent Human Force are required both at present and in the future and to achieve that, best practices are in reconciling the need of the employees in terms of health, and safety in workplaces in an organization. This study examines best practices, employee's occupational health and safety and the mediating role of organisational culture in a glass manufacturing company. The study uses responses from 350 employees of BETA Glass Company in Nigeria relying on regression analysis techniques and PLS structural equation modelling to test four hypotheses. This study validates the assumptions that training and development dimension of best practices positively impacts employee's health and safety in the workplace. This study affirms that leadership quality dimension of best practices fosters employee's health and safety in the workplace. Further, safe work procedures a dimension of best practices promote employee's health and safety in the workplace. Similarly, the result suggests that organisation culture mediates the relationship between best practices and employee's health and safety in the workplace. We, therefore, conclude that the relationship between best practices and employee's health and safety in the workplace is both linear and indirect..
\end{abstract}

Keywords: leadership quality, organisational culture, safe work procedures, training and development. JEL:M0, M10, M53

\section{Introduction}

Organisations that aspire to sustain their competitive edge, both at present and in the future require competent Human Force (Employees). More so, $21^{\text {st }}$-century challenges call for employees that are well equipped with recent techniques and technologies. Despite the application of technology in the modern business organisations, human resources are still relevant and most adaptive resources of the organisation (Hoang, Vu \& Ngo, 2020). Today's organisation is faced with several demands such as recruitment, and selection criteria (e.g. Ekwaoba, Ikeije \& Infoma, 2015), managing unethical behaviour (e.g. Cremer \& Vandekerckhove, 2017), sustaining employee commitment to strategy implementation (e.g. Nwachukwu, Žufan \& Chládková, 2020), job environment, ensuring customers satisfaction (Nwachukwu, Žufan \& Chládková, 2020), achieving superior organisational performance (e.g. Salau, Adeniji \& Oyewunmi, 2014), investigating favouritism, (Alwerthan, 2016), technical 
and behavioural competence and performance evaluation (Albino, 2018), nepotism, cronyism and favouritism (Shabbir \& Siddique, 2017), inclusive leadership, workplace spirituality organisational commitment and organisation citizenship behaviour (Utami, Sapta, Verawati \& Astakoni, 2021; Tran \& Choi, 2019), strategic leadership and business sustainability (Vu $\&$ Nwachukwu, 2020), role ambiguity, competency and person-job fit (June \& Mahmood, 2011) and individual and social factors affecting occupational Accidents (Barkhordari, Malmif \& Malakontikhah, 2019). The strategic value of best practice application stems from the fact that managers are endowed with discretionary decision-making power which can be exercised in health upliftment of the employees. The whole essences of best practices in an organisation are in reconciling the need of the employees in terms of health, and safety in workplaces. Although management focus towards best practices has increased of late, management literature reveals a relatively limited study on best practices and employee's health and safety at the workplace. Yet, there is more to understand in terms of how contextual factors such as organisational culture empowers or restrict the relationship between best practices and employee's health and safety in the workplace. Few efforts examining its implementation on employees health and safety measures in workplace focused on the general characteristics and the impact of occupational health and safety measures on employees' performance (e.g. Gbadago, Amedone \& Honyenuga, 2017, Gaceri, 2005, Lorincova, 2015), analysis of individual, leadership and supervisor support as social factors affecting employee faith and safety at the workplace (Barkhordari, Malmir, \& Malakoutikhah, 2019, Molnar et al., 2019, Yanar, Lay \& Smith, 2019) and organisational culture in leadership (Xue, 2019). Other scholars examined integrated Best practices with other extrinsic cues (e.g., Corporate governance, ethical leadership, employees' creativity, corporate social responsibility, ethical organisational culture, the business judgment rule and Human rights) and employees safety measure and management policies (Ozuomba, Onyemaechi \& Ikpeazu, 2016, Elqassaby, 2018, Selcuk, 2019, Debode, Avmenakis, Field \& Walker, 2013, Wilson, 2013). Other Best practices - related research includes studies measuring best practices for workplace safety, health and wellbeing (Jonathan \& Mbogo, 2016, Sorensen et al., 2019), organisational ethical culture and whistleblowing (FArooqi, Abid \& Ahmed, 2017), ethical leadership and injury management (Taufek, Zuikifle \& Abdulkadiri, 2015, Oketunji, 2014, Khan \& Javed, 2018, Alshammari, Almutairi \& Thuwalnl, 2015). Despite several studies on the subject, both conceptual and contextual gap exists. The understanding and application of best practices, leadership, training and development of employee's and safe work procedures vary across nations, continents, and regions. The present study attempt to narrow this knowledge gap. The objective of this paper is to contribute to the management literature by examining the impact of the implementation of Best practices (leadership, training and development for newly employed staff, safe work procedures) on employees' health and safety. Second, ascertain whether organisational culture mediates the relationship between Best practices and employee's occupational health and safety measures.

\section{LiteratureReview}

\subsection{Theoretical Perspective}

Beer's concept of human resource management and the integration of agency and system concept of safe lifestyle are included in this research. Beer's human resource management 
framework suggests that the job system has long-term implications for employers' or employees' health, in addition to affecting loyalty, competency, cost-effectiveness, and congruence. There is proof that the way people function has an effect on their physical and emotional health, as well as the length of their lives. Employees and their dependents struggle and lose money as a result of ill-health and accidents sustained by the work system or working conditions.Managers and supervisors must serve as role models (ensure best practices measures) for the safety programs. The convergence of agency and structure theory of healthy lifestyle was established by William Cockerham in 2005. This theory incorporates the concepts of agency and structure to show that in today's society, not everybody has the same opportunity to be well. It uses the term agency to correspond to a person's right to choose their behaviour and to emphasise that there may be other choices that the person does not choose. The Cockerham agency structure theory of healthy lifestyles shows that merely wanting to be healthy isn't always enough; personal improvements will, without a doubt, make an individual healthier. These theories are appropriate to explain that day-day activities, jobs and behaviors are empowered or constrained by social-physical environment factors. It reveals that the actions or behaviors of employees determines their health status which can as well affect their productivity at the workplace.

\subsection{An Overview of Employees' Workplace Health and Safety Measures}

The concern for health and safety has been there in history. Early researchers were concerned about the theoretical insight into employees' health and safety. Surveys which have been done later focused on the importance of legislation. According to Linhard (2005), firms focus their attention on occupational health and safety performance because of its potential for influencing productivity and workplace health and safety. Indeed, employee's health and safety awareness call for implementing best practices to address the problems of economic cost, performance, training and development, leadership qualities and safe working procedures in an organization. Employees are protected from hazards in the workplace by company healthcare and regulations on occupational health and safety practises. This requires adherence to safety guidelines, responsiveness to health and safety concerns, safety communication procedures, hazard detection and prevention, and reimbursement to workers in the event of permanent disability. The effectiveness of an occupational health and safety management system is influenced by employee engagement. This system is made up of a number of processes and mechanisms that encourage workers to participate in decision-making in both direct and indirect ways (Pavolowska, 2013). The active involvement of workers is emphasized as a crucial element in enhancing safety efficiency in the occupational health and safety management system model (Walters \& Frick, 2000). Employee involvement in an occupational health and safety management system is intended to eliminate workplace accidents and increase employee health. The active involvement of workers is emphasised as a crucial element in enhancing safety efficiency in the occupational health and safety management system model (Walters \& Frick, 2000). Enforcement of regulations is very vital in ensuring the efficacy of regulations. Idubor and Osiamoje (2013) opine that regulation without proper enforcement is tantamount to no laws. They go on to say that a lack of strict implementation of workplace safety and health laws encourages non-compliance. Occupants in factories are normally required to register their workplaces. Workplace safety and health laws and bills have been in place in Nigeria since the 1974 Labor Act and the passing of the labour, defence, health, and welfare bill in 2012.The factories Act of 1987 (now identified as the factory Act of 1990), which Kalejaiye (2013) defines as a significant updating of the 
factory Act of 1958, the workman's compensation Act of 1987, the labour Act of 1990, the workman's compensation Act of 2004, and the workers' compensation Act of 2011 (which repeals the workman's compensation Act of 2004) were all passed around this period.The factory Act of 1987, for example, excludes the building industry from the scope of its premises (Idoro 2008, 2011, Diugwu, Baba, \& Egila 2012), leaving the industry unregulated. According to Idubor and Osiamoje (2013) and Okojie (2010), the severity of penalties stipulated by Nigerian workplace safety and health laws are negligible since criminals are not detained. Thankfully, the new bill (the labour, safety, health, and welfare law of 2011), which stipulates strict penalties for violations, fixes all of the above concerns. It includes both Nigeria's formal and informal manufacturing sectors. The proposed bill aims to repeal the Factory Act and replace it with robust worker safety and health regulations.

\subsection{Training and Development}

Managers play a critical role in assisting workers in their learning and development within a company. To achieve this, managers must coach, guide and support employees. Training and development as well as a conducive work environment promote employee satisfaction and productivity in the workplace (Nwachukwu, Žufan \& Chládková, 2020). Employee preparation, it is argued, would enable them to be more efficient and provide a better working atmosphere. To do so, workers must go through orientation training, which introduces them to workplace specifications and how to complete delegated tasks. According to Ali, Abdullah, and Subramaniam (2009), the ineffectiveness of safety preparation would lead to a rise in workplace accidents and injuries. Safety preparation is intended to protect both staff and company property from physical injury. This require physical precautions like how to keep factories, computers, appliance machinery, and houses in good working order.Torrington, Hall and Taylor, (2005) opine that safety training should inform employees about the nature of the hazard at the workplace, the safety rules and procedures in case of emergency and the need to enforce compliance to these rules. Safety training needs to be done during induction, on the job and in refresher courses. Lectures, discussions, films, role-playing, and slides are some of the teaching methods that can be used. Posters, safety advertising programs and correspondence, and corrective procedures for violations of safety codes should be used to complement these approaches. Employees, it is arguable, should be educated on essential safety precautions that could help reduce the effects of threat exposure or accident risk. Workplace protocols and practices, as well as occupational health and safety training and encouragement, are examples of these preventive interventions. Occupational health and safety programs and protocols are implemented at the workplace level to shield workers from hazard exposure and workplace harm.

\subsection{Leadership Quality}

The method of motivating workers to do their best in order to accomplish the desired outcome is known as leadership. It's also known as the power to convince people to change their minds. The defence, wellness, and well-being of workers was clearly prioritised by leadership around the board. Leadership encourages prosocial behaviour and helps businesses succeed (Salim \& Rajput, 2021). Managers have the tools and atmosphere required to foster a positive working environment. To ensure workers' safety, fitness, and well-being, leaders must have the tools required to enforce best practises.Establishing responsibility for the execution of appropriate policies and practises, as well as efficiently communicating these goals through 
formal and informal networks. Leaders that lead by example and demonstrate commitment to maintaining health and safety measures perform higher (O'Brien, 2001). Via coordination with labour or workplace councils, management/leadership can include employees in health and safety issues. Employees will be aware of the rules that extend to them and will be able to respond to policy violations as a result of this (Kaplan, 2009). Where labour unions are recognised, leaders can meet with them together on health and safety issues, regardless of whether the unions are recognised.

\subsection{Safe Work Procedures}

A warning about the possible effects of deviation is included in safe job procedures. They are designed to outline the actions to take in order to complete a mission without risking injuries or sickness. Safe work procedure provides important and consistent information to employees of what is expected of them from a safety perspective. Implementing workplace safety and health at work effectively will increase working conditions. Occupational health and safety prevention is one of the management's practises for preventing workplace accidents and injury. Employees must perform an occupational hazard report to assess whether certain risks necessitate the use of PPE (PPE). Employees are more motivated to perform activities in a hostile environment while they are wearing personal protective gear, which leads to better results and efficiency.Furthermore, failing to use personal safety devices is a risky procedure that can result in injury. According to Fernandez Monies, Montes-peon, and Vazquez (2009), procedures, strategies, and interventions will help employees and businesses avoid injuries. According to Gopang, Nebhwan, Khatri, and Marri (2017), the availability of a written safety policy document may have an effect on an organization's efficiency. With procedures and activities that include working environments, the organization improves workforce safety, fitness, and well-being.To reduce the number of accidents in the industrial industry, employers should adopt and follow both occupational safety and health standards and procedures. Human errors can sometimes cause accidents and injuries to the employees, but this can be effectively managed with the implementation of robust safety measures by management. Griffins and Nean (2000) contend that injuries or accidents in the workplace may happen when employees ignore safety procedures.

\subsection{Organisational Culture as a Mediating Variable}

It is important to ensure that best practices measures are incorporated in a structure of the business process and it transformed into the organisational culture. Culture is the ideas, emotions and behaviour that express the social structure of groups of employees and are express by symbols that are created and transmitted (Cram et al., 2017). Organizational culture is related to how employees understand the cultural characteristics of an organisation. Organisational culture represents a common perception of employees of the organisation in otherwise; culture is a system of shared meaning. Culture believes that the collective learns through "external adaptation" and "internal integration" problem-solving (Nurkholis et al., 2020). We reason that the relationship between best practice (leadership, training and development for newly employed staff, safe work procedures) and employees health and safety is not straight forward. Organisational culture interacts with different factors to influence organisational outcomes. Arguably, organisations will need a robust culture to enjoy the benefit of implementing best practices. 


\subsection{Empirical Studies}

Dwomoh, Owusu and Addo (2013) examine the impact of health and safety policies on employee's performance and safe work procedures in the Ghana timber industry. The study has been employed interviews and questionnaires to collect data from participants. Pearson correlation has been used to assess the relationship between investment in health and safety and employee's performance in safe work procedure. The results suggest that health and safety is positively correlated with employee's performance and safe work procedures. It has been concluded that an organisation needs to pay attention to health and safety measures to enhance employee performance. Jan (2012) submits adherence to health and safety rules and procedures promote employee effectiveness and efficiency resulting in better performance of employees. Chikono (2017) observes that business leaders created a safe work environment, trains and empowers employee with relevant skills. Mashi, Johanim and Subramaniam (2016) examine the relationship between safety training and workers involvement and health care workers safety behaviour. A survey of 229 nurses from Abuja Secondary Health facilities in Nigeria suggests that safety training is positively related to compliance and safety participation. Also, workers involvement positively relates to safety compliance and participation. Extant literature in occupational safety supports the view that safety training is a key factor in maintaining and changing workers attitude towards safety (e.g. Ali, Abdullah \& Subramaniam, 2009, Boughaba, Hassane \& Ronkia, 2014, Keffane, 2014). Petita, Probst and Barbaranelli (2017) report that bureaucratic safety culture is connected to moral disengagement whereas technocratic safety culture was associated with moral disengagement.

\subsection{Conceptual Framework}

This study examines the relationship between best practices as a predictor variable (the independent variable) and employees' health and safety measures as then criterion variable (the dependent variable) as shown in the figure (1). The dimensions of best practices in the framework are training and development, leadership quality, and safe work procedures. Organisational culture is playing a mediator role in the model.

Figure 1. Research model showing the relationship between the variables.

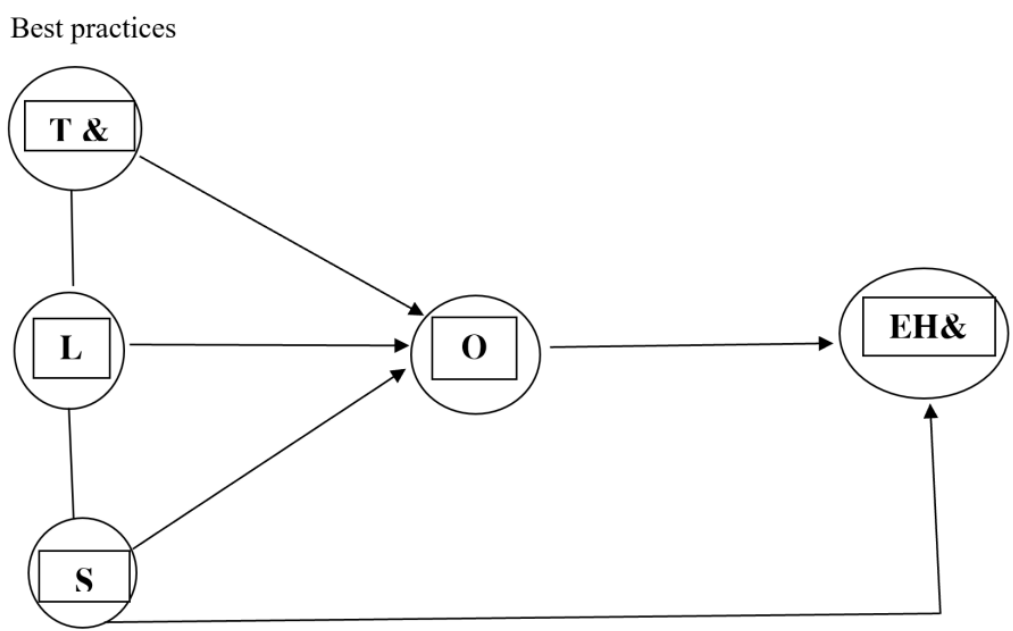


Where:T \& D = training and development, $\mathrm{LQ}=$ leadership quality, SWP= safe work procedures, $\mathrm{EH} \& \mathrm{~S}=$ employees' health and safety, $\mathrm{OC}=$ organisational culture.

\subsection{Research Hypothesis}

The following research hypotheses were stated in the Null form, and they are to determine if there is any significant relationship between each dimension of best practices and employees' health and safety measures in the workplace.

$\mathrm{H}_{1}$ : $\quad$ There is no significant relationship between training and development and employees' health and safety measures in workplace.

$\mathrm{HO}_{2}$ : There is no significant relationship between leadership quality and employees' health and safety measures in workplace.

$\mathrm{HO}_{3}$ : there is no significant relationship between safe work procedure and employees' health and safety measures in workplace.

$\mathrm{HO}_{4}$ : Organisational culture does not significantly mediate the relationship between Best practice and employee's occupational health and safety.

\section{Methodology}

This section outlines the methodology employed in the study. It went through the target population, sample size, data collection processes, and then a rundown of data processing and presentation techniques. The study's key goal is to look at the impact of best practises policies on employee health and safety in the workplace, as well as the mediating influence of organisational culture, in a manufacturing firm in Ughelli, Delta State (Beta Glass Company Plc, Ughelli).

\subsection{Research Questions}

The following analysis questions directed the investigation.

- To what extent do training and development affect employees' health and safety measures in a manufacturing company?

- To what extent does leadership quality affect employees' health and safety measures in a manufacturing company?

- To what extent do safe work procedures influence employees' health and safety measures in a manufacturing company?

- Does organisational culture mediate the relationship between best practice and employee occupational health and safety measures in a manufacturing company?

\subsection{Research Design}

The authors used case study survey research approach. The target population is all employees of BETA GLASS company in Ughelli in Delta State of Nigeria. The Glass company was of interest because it is considered as one of the biggest employers of labour in the industry. The total population of the study is 2850 staffs of Beta Glass Company, Ughelli. 


\subsection{Sample Size and Sampling Technique}

The sample size of study was determined by the use of TARO YAMANE formula $\mathrm{n}=\underline{\mathrm{N}}$

$1+\mathrm{N}(\mathrm{e})^{2}$

Where: $\mathrm{n}=$ sample size, $\mathrm{N}=$ population of study and $\mathrm{e}=$ error margin $(5 \%)$

$\mathrm{n}=\underline{2850}$

$\mathrm{n}=2850$

$$
1+2850(0.05)^{2}
$$

$1+2850(0.0025)$

$\mathrm{n}=2850$

$1+7.125$

$\mathrm{n}=\underline{2850}$

$\mathrm{n}=350$

The sample size is 350 . Hence, 350 copies of questionnaire were administered to employees of the various departments. The questionnaires were randomly distributed to participants.

\subsection{Research Instrument/ Questionnaires Design}

The respondents were asked to evaluate the impact of best practises on employee wellbeing and safety at work. We used structured questionnaires to elicit information from respondents. Primary data was obtained through self-administered Questionnaires. The structured questionnaires were divided into three sections; section A sought information on demographic variables, $\mathrm{B}$ asked questions relating to Best practices, while $\mathrm{C}$ elicits information about employees' health and safety. A five (5) point Likert scale was employed ranging from "strongly agree 5 to strongly disagree 1 ".

\subsection{Validity and Reliability of the Instrument}

To ensure the validity of the questionnaires, we developed it following the literature review. A draft of the questionnaires was sent to senior academics in the field of management to evaluate how well the questions asked affirms the review of the related literature. The term "reliability" refers to calculations of how free a measurement is from random or unsuitable error (Cooper \& Schindler, 2003). We conducted a pilot test using 20 copies of the questionnaires. Data analysis method employed involved quantitative procedures. Data were analysed using both descriptive and inferential statistical methods. Ordinary least square (OLS) regression and canonical correlation analysis were done PLS structural equation modelling was used to evaluate the mediating role of organisational culture. The study used STATA version 13.0 software for data analysis.

\subsection{Model Specification}

Employees' health and safety measures in workplace $=\mathrm{f}$ (Best Practices)

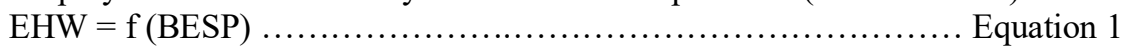

BESP $=($ TDEV, LQLT, SWPR) ................................ Equation 2

Equation (1) and (2) is expanded as follows: 
Model: $\mathrm{EOHW}=\alpha 0+\beta 1 \mathrm{TDEV}+\beta 2 \mathrm{LQLT}+\beta 3 \mathrm{SWPR}+\mathrm{Ui}$ Equation 3

Where:

BESP $=$ Best Practices

TDEV $=$ Training and Development

LQLT = Leadership Qualities

SWPR $=$ Safe Work Procedure

ORGC $=$ Organisational Culture

$\mathrm{EOHW}=$ Employees' health and safety measures in workplace

$\mathrm{Ui}=$ Stochastic Variables

$\mathrm{B} 1-\beta \mathrm{n}=$ Coefficients of Regression

$\alpha 0=$ The Intercept

\section{Results}

\subsection{Results.}

Table 1 indicates that the structures have a maximal value of 5, showing that all of the questions were answered with clear agreement at some stage. The average response is 4 (Agree), indicating that the respondent agrees with the questions.

\begin{tabular}{|c|c|c|c|c|c|}
\hline stats I & tdev & lqlt & swpr & orgc & eohw \\
\hline$\cdots+\cdots+\cdots$ & $\cdots-\cdots$ & $\cdots-\cdots,-\cdots$ & 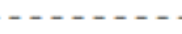 & 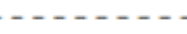 & $\cdots$ \\
\hline mean I & 4.277143 & 4.285714 & 4.345714 & 4.311429 & 4.291429 \\
\hline p50 & 4 & 4 & 4 & 4 & 4 \\
\hline $\max$ & 5 & 5 & 5 & 5 & 5 \\
\hline min & 3 & 3 & 3 & 3 & 3 \\
\hline $\mathbf{N}$ & 350 & 350 & 350 & 350 & 350 \\
\hline
\end{tabular}

Source: Authors 2020

The result in table 2 suggests that training and development $(r=0.630)$, leadership quality $(\mathrm{r}=0.669)$, safe work procedures $(\mathrm{r}=0.587)$, and organisational culture $(\mathrm{r}=0.433)$ are positively correlated with employees' occupational health and safety. This implies that both the dependent and independent variable move in the same direction. Thus, as the company implement best practices employees' health and safety in the workplace will improve.

Table 2. Correlation Result

\begin{tabular}{|c|c|c|c|c|c|}
\hline | & tdev & lqlt & swpr & orgc & eohw \\
\hline$\cdots-1$ & 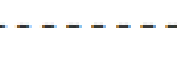 & $\cdots$ & $\cdots$ & & \\
\hline tdev & 1.0000 & & & & \\
\hline lqlt & 0.6564 & 1.0000 & & & \\
\hline swpr & 0.5181 & 0.5282 & 1.0000 & & \\
\hline orgc & 0.4616 & 0.4554 & 0.4636 & 1.0000 & \\
\hline eohw & 0.6301 & 0.6693 & 0.5875 & 0.4334 & 1.06 \\
\hline
\end{tabular}

Source: Authors 2020 
Table 3. Multiple Regression

\begin{tabular}{|c|c|c|c|c|c|c|c|}
\hline Source I & SS & $d f$ & \multicolumn{2}{|c|}{ MS } & & \multicolumn{2}{|l|}{ Number of obs $=$} \\
\hline & & $-\cdots$ & $-\cdots$ & $-\cdots$ & & $F(3, \quad 346)$ & 145.84 \\
\hline Model | & 67.1607545 & 3 & 22 & 9182 & & Prob > F & 0.0000 \\
\hline Residual | & 53.1135313 & 346 & .15 & 7316 & & R-squared & 0.5584 \\
\hline------++ & $\ldots \ldots$ & $-\cdots$ & $-\cdots$ & $-\cdots$ & & Adj R-squared & 0.5546 \\
\hline Total | & 120.274286 & 349 & .3 & 2546 & & Root MSE & .3918 \\
\hline eohw I & coef. & std. & Err. & $\mathrm{t}$ & $P>|t|$ & {$\left[\begin{array}{ll}95 \% & \text { Conf. }\end{array}\right.$} & Interval] \\
\hline & 2559699 & ana & ( & 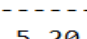 & a gag & 159237 & 3526819 \\
\hline tdev I & .2559609 & .049 & 772 & 5.20 & 0.000 & .159237 & .3526849 \\
\hline lqlt & .3696317 & .0505 & $\$ 323$ & $7 \cdot 31$ & 0.000 & .2702425 & .4690208 \\
\hline swpr I & .2671226 & .0442 & 2412 & 6.04 & 0.000 & .1801072 & .354138 \\
\hline _cons I & .4516727 & .186 & 604 & 2.43 & 0.016 & .0857208 & .8176246 \\
\hline
\end{tabular}

Source: Authors 2020

Table 4. PLS-SEM

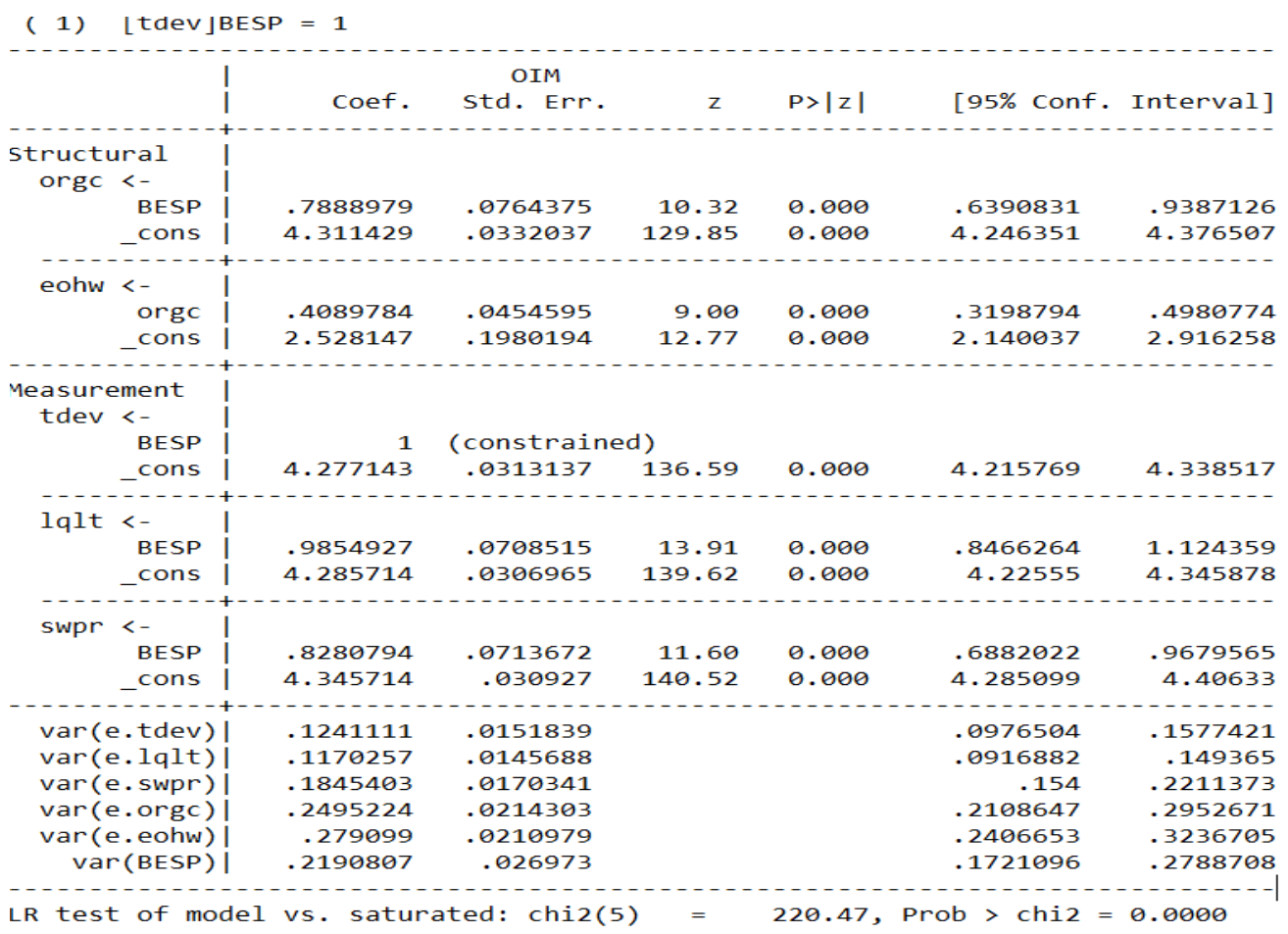

Source: Authors 2020

\subsection{Discussion.}

The modified R-squared value of 0.55 in the multiple regression findings in table 3 indicates that best practises clarified 55 percent of the systemic differences in workers' health and safety policies in the workplace. The multiple regression analysis is statistically important on the whole, with an F-statistic of 145.8 and a P-value of 0.000. Furthermore, the regression findings in Table 3 indicate that preparation and growth $(\mathrm{B}=0.2559, \mathrm{P}=0.000)$ has a significant association with occupational health and safety in the workplace $(\mathrm{B}=0.2559, \mathrm{P}=$ 
0.000). The null hypothesis was shown to be false, while the alternative hypothesis was found to be true (H1).This supports the works of (Mashi, Johanim \& Subramaniam, 2016; Ali et al., 2009; Boughaba et al., 2014; Keffane, 2014). In their submission that training is usually used as a key requirement for compliance and participation to achieve optimal safe working environment and to improve employee competence. There is a significant association between leadership efficiency and workers' health and safety policies in the workplace $(=0.3696, \mathrm{p}=$ 0.011). As a result, the null hypothesis (Ho) was dismissed, while the alternative hypothesis (H2) was adopted, meaning that there is a substantial connection between leadership efficiency and workplace occupational health and safety policies. This is in line with Chikono (2017), who claims that corporate leaders should promote a healthy work atmosphere by preparing the work to be done, how the mission will be completed, and when it will be completed.Preventing social and environmental damage in the workplace improves employees' wellbeing and standard of living (Ho, Vu \& Vu, 2020). Training empowers and equips employee with relevant skills. Safe work procedure $(\beta=0.2671, p=0.000)$ indicates that there exists a significant relationship between safe work procedure and employees' health and safety measures in the workplace. As a result, the null hypothesis (Ho) was dismissed and the alternative hypothesis $(\mathrm{H} 3)$ was adopted, suggesting that there is a substantial connection between healthy work procedures and occupational health and safety policies. This backs up the claims made by Dwomoh, Owusu, and Addo (2013) and Jan (2012) that if employees understand the health and safety laws, procedures, and equipment used in operations, they can function more efficiently, resulting in improved results. Additionally, as workers are kept safe at work, they feel respected. This allows workers to achieve corporate excellence by doing very well on the job.The mediating impact of organizational culture was investigated using PLS Structure equation modeling (PLS-SEM). The route analysis results in figure 2 and table 4 reveal that organizational culture mediates the relationship between best practices and workers' health and safety policies at work. As a result, the null hypothesis (Ho) was dismissed, while the alternative hypothesis (H4) was adopted, meaning that organizational culture mediates the interaction between best practices and workers' occupational health and safety policies.This backs up Petitta, Probst, and Barbaranelli's (2017) claim that a positive safety culture is linked to better safety results. This link is optimistic, indicating that a more positive safety atmosphere is linked to better safety results. These findings suggest that there is a direct and indirect connection between best practices and workplace occupational health and safety.

\section{Conclusion}

The aim of this research was to determine the effect of best practices on employee health and safety in the workplace. It's fascinating to learn that in Nigeria, best practices foster employee health and safety at work. The implications of adopting Best practices in terms of their positive effect on protecting and fostering workplace protection, welfare, and wellness are becoming increasingly clear. For employee health and safety in the workplace, best practices such as preparation and growth, healthy job processes, and leadership efficiency in terms of supervising positions of managers are critical.This highlights the importance of emphasizing Best practices in healthy and safety in the workplace. Organizations must implement innovative plans and strategies to achieve competitive edge (Nwachukwu, Žufan \& Chládková, 2020). In this context, companies can accomplish their strategic objectives by 
adopting innovative ideas to ensure health and safety of employees. The study concluded that Best practices protect, preserve the health and safety of employees of Beta Glass Industry, a manufacturing company in Delta State to a large extent. Training and development, safe work procedure and leadership quality can result in an improvement in health and safety measures at the workplace. Managers need to share information, skills with employees, create an individualised relationship with employees in health and safety. It is believed that providing greater autonomy to employees on health and safety matters will add value to the company.

In terms of the recommendation, given the stated findings and conclusions, the authors propose the following suggestions that could assist managers to implement Best practices that will enhance employee's health and safety measures in the workplace:

- $\quad$ Employees training and development activity should be used to identify knowledge, skills and competency deficit in an organisation to improve and comply with regulations guiding employees at work.

- Manufacturing firms should give attention to health and safety issues.

- Manufacturing firms must ensure financial and non-financial reward packages in employees who might be disabled due to accident or fire outbreak in their line of duty.

- $\quad$ Manufacturing firm must ensure that organisational culture must be binding on all employees, both contract and permanent staffs in hospitality, treating and dispensing of drugs and protective equipment to workers.

As for the managerial implications, the outcome of the present study will be useful for manufacturing industry managers as they search for ways to improve best practice measures and minimise the occurrence of hazards and mishap in organisations. The study informs employees, managers, governmental agencies, human right activist and the society in general. Knowledge of such information will facilitate a better understanding of best practices that promote employee health and safety and implement them accordingly. Indeed, this study defines how best practice flows in the manufacturing sector in Nigeria. The study contributes to the management literature by highlighting how the implementation of Best practices foster employee's health and safety in the workplace. Finally, the study suggests that the relationship between best practices and employees' health and safety in the workplace is both straight forward and indirect.

Also, there are some limitations and suggestions for future study. While our findings may be limited to the context examined, that is a single case study. Nevertheless, the present study enriches scholarship on management and employee wellbeing. Further study should examine the subject by using data from more companies in different geographical contexts. Scholars can introduce other contextual factors or organisational characteristics to determine if the result will be different from the present study.

\section{References}

[1] Albino. G. (2018). Technical and Behavioural competencies on performance evaluation: Petrek leaders perspectives. Sage open, April-June, 1-12

[2] Ali, H., Abdullah, N. A \& Subramaniam, C. (2009) Management Practices in Safety Culture and its Influence on Workplace Injury an Industry in Malaysia. Disaster Prevention and Management, 18(5), 470-477.

[3] Alshammari, A., Almutairi, N. \&Thuwaini, S. (2015). Ethical leadership the effect on employees International Journal of Business and Management, 10(3), 108-116.

[4] AlwerThan, T. A. (2016). Investigating favouritism from a psychological lens. The Journal of Values-Based leadership, 9(2), 1-10.

[5] Barkhordari, A., Malmir, B.\& Malakoutikhah, M. (2019). An Analysis of individual and social factors affecting occupational Accidents. Safety and health at work, 10(2), 205-212. 
[6] Boughaba, A, Hassane, C, \& Roukia, O. (2014). Safety culture assessment in petrochemical industry: a comparative study of two algebraic plants. Safety and Health at Work, 5(2), 60-65.

[7] Chikono, N. N. (2017). Leadership practices that improve the workplace safety environment. Walden university scholars works. Walden dissertation and doctoral studies collections.

[8] Cockerham, W. C. (2005). Health lifestyle theory and the convergence of agency and structure. Journal of Health and Social Behaviour, 461(6), 46-105.

[9] Cooper, D. R. \& Schindler, P. S. (2003). Business Research Methods (8th eds). USA: McGraw-Hill.

[10] Cram, W. A., Proudfoot, J. G., \& D'arcy, J. (2017). Organizational information security policies: a review and research framework. European Journal of Information Systems, 26(6), 605-641.

[11] Cremer, D. D.\& Van Dekerckhove, W. (2017) managing unethical behaviour in organizational the need for a behavioral business ethics approach. Journal of Management and Organisational, 23(3), 437-455.

[12] Debode, N. D., Armenakis, A. A., Field, H.\& Walker, A. G. (2013). Assessing ethical organizational culture: refinement of scale. This Journal of Applied Behaviour Science, 49(4), $460-484$.

[13] Diugwu, I. A., Baba, D. L.\& Egila, A. E. (2012). Effective Regulation and Level of Awareness and Expose of the Nigerian Construction Industry, Open Journal of Safety Science and Technology2, 140-146

[14] Dwomoh, G, Owusu, E. E.\& Addo, M. (2013). Impact of occupational health and safety policies on employees' performance in the Ghana Timber industry. Evidence from Lumber and Logs limited. International Journal of Education and Research, 1(12), 1-14.

[15] Ekwoaba, J. O., Ikeije, U. U.\& Ufoma, N. (2015). The impact of recruitment and selection criteria on organisational performance. Global Journal of human resources management, 3(2), 22-33.

[16] Elqassaby, H. K. (2018) The effect of ethical leadership on employees' creativity. International Journal of Economics and Management Science, 7(5), 1-13.

[17] Farooqii, S., Abid, G.\& Ahmed, A. (2017). How bad it is to be good: impact of organizational ethical culture on whistleblowing (the ethical partners). Arab Economics and Business Journal, $12(2), 69-80$

[18] Fernandex-Miniz, B., Montes-Peon, J. M. \& Vazquez-Ordas, C. J. (2014). Safety leadership, risk management and safety performance in Spanish firms. Safety Science70, 295-307.

[19] Gaceri, K. A. (2015). Factor affecting the implementation of health and safety in supermarkets in Kenya. International Journal of Human Resource Studies, 5(2), 223-281.

[20] Gbadago, P., Amedome, S. N.\& Honyenuga, B. Q. (2017). The impact of occupational health and safety measures on employees' performance at the South Tongu District hospital. Global Journal of medical research: K Interdisciplinary, 17(5), 13-19.

[21] Gopang, M. A., Nebhwani, M., Khatri, A \& Mairi, H. R. (2017). An Assessment of Occupational Health and Safety Measures and Performance of SMEs: An Empirical Investigation. Safety Science93, 127-133.

[22] Griffin, M. A \& Neal, A. (2000). Perception of safety at work: a framework for linking safety climate in safety performance, knowledge and motivation. Journal of Occupational Health Psychology, 5(3), 347-58.

[23] Ho, T. T. H., Vu, T. N. P. \& Vu, H. M. (2020). Determinants Influencing Consumers Purchasing Intention for Sustainable Fashion: Evidence from Ho Chi Minh City. Journal of Asian Finance, Economics and Business, 7(11), 977-986.

[24] Hoang, L. V., Vu, H. M.\& Ngo, V. M (2020). Corporate Social Responsibility and Job Pursuit Intention of Employees in Vietnam. Journal of Asian Finance, Economics and Business, 7(12), 345-353.

[25] Idoro, G. I. (2008). Health and safety management effort as correlate of performance in the Nigeria construction industry. Journal of Civil Engineering and Management, 114(4), 277-285 
[26] Idoro, G. I.(2011). Comparing Occupations Health and Safety (OH8) Management Efforts and Performances of Nigeria Construction Contractors. Journal for Construction in Developing Countries, 16(92), 151-173

[27] Idubor E. E. \& Osiamoje, M. D. (2013). An exploration of health and safety management issues in Nigeria's Effort to Industrialize. European Scientific Journal, 9(12), 154-169.

[28] Jan, R. (2012). Cost and Benefits of Implementing an Occupational Safety and Health Management System (OSH MS) in Enterprises in Poland. International Journal of Occupational Safety and Ergonomics, 18(2), 181-193.

[29] Jonathan, G. K. \& Mobogo, R. W. (2016). Maintaining health and safety at workplace. Journal of Education and Practice, 17(29), 1-7.

[30] June, S. \& Mahmood, R. (2011) The relationship between role ambiguity, competency and person-Job fit with the job performance of employees in the service sector SMEs in Malaysia. Business Management Dynamic, I(2), 79-98.

[31] Kalejaiye, P. O. (2013). Occupational health and safety: issues, challenges, and compensation in Nigeria. Peak Journal of Public Health and Management, 1(2), 16-23.

[32] Kaplan, N. (2009). Understanding People ManagementKaplan Business Books, London: Kaplan

[33] Keffane, S. (2014). Communization role in safety management and performances for road safety practices. International Journal of Transportation Science and Technology, 3(1), 79-94

[34] Khan, S. R. \& Javed, U. (2018). Revision of ethical leadership scale. Journal of research and reflections in education, 12(2), 121- 135.

[35] Linhard, J. B. (2005). Understanding the return on health safety and environmental Investment. Journal of Safety Research, 36(3), 257-260.

[36] Lorincova, S. (2015). The improvement of the effectiveness in the recruitment process in the Slovak public administration. Procedia Economics and Finance34, 382-389.

[37] Mashi, S, Johanim, J. \& Subramaniam, C. (2016). The effects of safety training and workers involvement on healthcare workers safety behaviours: the moderating role of consideration of future safety consequences. International Journal of Business Management, 1(2), 46-81

[38] Molnar, M. M., Schwartz, U.V.T., Hellgrem, J., Hasson, H \& Tafuelin, S. (2019). Leading four safety: a question of leadership focus. Safety and Health at Work,10(2) 180-187.

[39] Nurkholis, N., Dularif, M., \& Rustiarini, N. W. (2020). Tax evasion and service-trust paradigm: A meta-analysis. Cogent Business \& Management, 7(1), 1-20.

[40] Nwachukwu, C., Žufan, P \& Chládková, H. (2020). Employee commitment to strategy implementation and strategic performance: organisational policy as moderator. International Journal of Business Excellence, 20(3), 398-418.

[41] O'brien, P. D. (2001). The Safety Officer Concise Desk Reference, London: Lewis Publishers.

[42] Oketunji, S. F. (2014). Influence of occupational health and safety (OHS) information availability and use on job performance of library personal in public universities in South-West Nigeria. European Scientific Journal10, 337 - 350.

[43] Okojie, O. (2010). System for reporting occupational disease in Nigeria: African Newsletter on Occupational Health and Safety, 20(93) 51-53.

[44] Ozuomba, N., Onyemachi, U. \& Ikpeazu, N. (2016). Effects of corporate governance on organisational performance: A case study of Nigeria Breweries Plc, Enugu State. International Journal of Management Science and Business Research, 5(11), 1-21.

[45] Petitta L., Probst, T. M. \& Barbaranelli, C. (2017). Safety Culture, Moral Disengagement, and Accident Underreporting. Journal of Business Ethics 141, 489-504.

[46] Salau, A. A.\& Oyewunmi, A. (2014). Relationship between element of job enrichment and organizational performance among the non-academic staff in Nigeria public universities. Management and Marketing, 11(2), 173-189.

[47] Salim, A. \& Rajput, N. A. R. (2021). The Relationship Between Transformational Leadership, Prosocial Behavioral Intentions, and Organizational Performance. Journal of Asian Finance, Economics and Business, 8(1), 487-493. 
[48] Shabbir, B. \& Siddique, H. (2017). Impact of nepotism, cronyism and favouritism on organisational performance with a strong moderator of Religiosity. International Journal of Scientific and Engineering Research, 8(4), 29-309.

[49] Sorensen, G., Sparer, E., Williams, J. A. R., Gundersen, D., Boden, L. L., Dennerlein, J. T., Hashimoto, D., Kafz, J. N., Mclellani, D., Okechukwu, C. A., Pronk, N. P., Revette, A \& Wagner, G. R. (2019). Measuring best practices for workplace safety health and wellbeing: the workplace integrated safety and health assessment. Journal of Occupational and Environmental Medicine, 60(5), 430 - 439.

[50] Taufek, J. H. B. M., Zulkifle, Z. B.\& Aldul Kadir, S. Z. B. (2016). Safety and health practice and injury management in manufacturing industry. Procedia Economics and Industry35, $705-$ 712.

[51] Torrington, D., Hall, L. \& Taylor, S. (2005). Human Resource Management (6th Edition). Financial Times: Prentice Hall - Harlow.

[52] Tran, T. B. H. \& Choi, S. B. (2019). Effects of inclusive leadership on organisational citizenship behaviours: the mediating roles of organisational justice and learning culture. Journal of Pacific Rim Psychology, 13(17), 1-11.

[53] Utami, N. M. S., Sapta, K. S., Verawati, Y \& Astakoni, M. P. (2021). Relationship between Workplace Spirituality, Organizational Commitment and Organizational Citizenship Behavior. Journal of Asian Finance, Economics and Business, 8(1), 507-517.

[54] Vu, H. M. \& Nwachukwu, C. (2020). Human resources, financial resources and strategic performance: Organisational policy as moderator. Quality-Access to Success Journal, 21(175), $18-24$.

[55] Walters, D. R \& Frick, K. (2000). Workers participation on the management of occupational health and safety reinforcing or conflicting strategies? In K, Frick, L, P, Jesen, M, Quinlan and with Agen Eds, Systematic Occupational Health and Safety Management - Perspectives on an International Development, Pp 43-65, Pergamon Press, Oxfords, Uk.

[56] Wilson, N. (2013) Corporate social responsibility the business judgment rule and human right in Australia- warm inner glow or warming the globe. Monash University Law Review, 38(3), 148-167.

[57] Xue, Y. (2019). The influence of organisational culture on leadership: a case studies of Baidu Corporation, China. Asian Journal of Social Science, 4(4), 86 - 106.

[58] Yanar, B., Lay, M. \& Smith, P. M. (2019). The interplay between supervisor safety support and occupational health and safety vulnerability on work injury. Science Direct Oshri, Safety and Health at Work 10, 172-179. 